\title{
Laboreal
}

Volume $6 \mathbf{N}^{\circ} 1$ | 2010

Varia

\section{O contributo do design ergonómico na interacção com dispositivos de controlo : um caso de reconcepção de um posto de trabalho}

La contribución del diseño ergonómico para la interacción con dispositivos de control : un caso de rediseño de un puesto de trabajo La contribution du design ergonomique dans l'interaction avec les dispositifs de contrôle: un cas de (re)conception d'un poste de travail The contribution of ergonomic design to the interaction with control displays : a case of redesign of a work station

\section{Sara Ramos, Inês Gonçalves, Hugo Simões e Francisco Rebelo}

\section{OpenEdition}

\section{Journals}

\section{Edição electrónica}

URL: http://journals.openedition.org/laboreal/9080

DOI: $10.4000 /$ laboreal. 9080

ISSN: 1646-5237

\section{Editora}

Universidade do Porto

\section{Refêrencia eletrónica}

Sara Ramos, Inês Gonçalves, Hugo Simões e Francisco Rebelo, «O contributo do design ergonómico na interacção com dispositivos de controlo : um caso de reconcepção de um posto de trabalho », Laboreal [Online], Volume $6 \mathrm{~N}^{0} 1 \mid$ | 2010, posto online no dia 01 julho 2010, consultado o 10 outubro 2019. URL : http://journals.openedition.org/laboreal/9080 ; DOI : 10.4000/laboreal.9080

Este documento foi criado de forma automática no dia 10 outubro 2019.

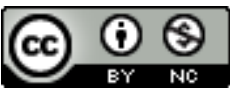

Laboreal está licenciado com uma Licença Creative Commons - Atribuição-NãoComercial 4.0 Internacional. 


\section{O contributo do design ergonómico na interacção com dispositivos de controlo : um caso de reconcepção de um posto de trabalho}

La contribución del diseño ergonómico para la interacción con dispositivos de control : un caso de rediseño de un puesto de trabajo

La contribution du design ergonomique dans l'interaction avec les dispositifs de contrôle : un cas de (re)conception d'un poste de travail

The contribution of ergonomic design to the interaction with control displays : a case of redesign of a work station

Sara Ramos, Inês Gonçalves, Hugo Simões e Francisco Rebelo

\section{NOTA DO EDITOR}

Manuscrito recebido em : Fevereiro/2010

Aceite após peritagem : Abril/2010

\section{Introdução}

\subsection{A problemática das LME : do reconhecimento à prevenção}

1 Os efeitos positivos da intervenção ergonómica na segurança, no bem-estar dos trabalhadores e na produtividade é larga- mente reconhecido na literatura (Shikdar \& Das, 1995). No entanto, a introdução de alterações nas situações de trabalho requer alguns aspectos a considerar, nomeadamente no que se refere a intervenções no âmbito do design ergonómico. 
2 Apesar do inegável progresso da automatização e da mecani- zação, algumas situações de trabalho permanecem muito de- pendentes do trabalho manual (incluindo, por exemplo, tarefas como puxar, arrastar ou empurrar). Neste contexto, o estudo do trabalho manual permanece um tópico de interesse para os investigadores (Looze et al., 2001), nomeadamente pela relevância das suas consequências ao nível das lesões músculo-esqueléticas (LME). Apesar de nos países industrializados, as LME constituírem a forma mais comum de doença profissional (Colombini \& Occhipinti, 2006), a investigação neste domínio foca-se, frequentemente, mais no seu reconhecimento do que na efectiva prevenção (Coutarel, Daniellou \& Dugué, 2005).

3 Desde o final dos anos 80 que a problemática das LME se tornou um campo privilegiado da intervenção ergonómica, dado o aumento das situações declaradas que se fez sentir a partir desta altura (Bourgeois \& Hubault, 2005). A relação entre este tipo de patologias e diversos aspectos da organização do trabalho (nomeadamente, a repetitividade, a duração e o ritmo de trabalho, as pausas, etc.) é actualmente aceite e reconhecida (Colombini \& Occhipinti, 2006). Neste sentido, a intervenção no âmbito desta problemática incide frequentemente nos as- pectos atrás referidos, revelando uma abordagem focada no plano biomecânico e que concebe a perturbação músculoesquelética enquanto resultado de uma combinação patogénica de factores biomecânicos e psicossociais (Coutarel, Daniellou \& Dugué, 2005). 0 acentuado aumento da incidência das LME levou a ergonomia a repensar as relações entre saúde e organização do trabalho, revelando que este tipo de abordagens centradas nos aspectos biomecânicos tem-se demonstrado pouco adequado e que uma prevenção eficaz requer, como defendem Bourgeois e Hubault (2005), uma mudança no "perímetro" da intervenção.

4 A compreensão dos problemas músculo-esqueléticos centrada no gesto e na evolução dos constrangimentos gestuais (inten- sificação do constrangimento temporal; automatização e mecanização progressivas das situações de trabalho) tem sido dificilmente sustentada no terreno, como se o "gesto" revelas-se as "tensões da pluridisciplinaridade ergonómica" (Bourgeois \& Hubault, 2005, p. 22). A solicitação músculo-esquelética (ou o "gesto") representa um aspecto importante da actividade e deve ser pensada não isoladamente mas enquanto parte integrada da actividade e contributo quer para a performance quer para a prevenção, o que implica uma compreensão dos modos operatórios e dos determinantes da actividade (Vézina, 2001 ; Bourgeois \& Hubault, 2005).

De facto, as evoluções das formas de organização do trabalho implicam transformações importantes na actividade concreta. Neste ponto de vista, é possível conceptualizar as perturbações músculo-esqueléticas enquanto reveladoras de uma insuficiente margem de manobra deixada ao trabalhador. Esta segunda abordagem assenta no reconhecimento da relação subjectiva que o trabalhador estabelece com o seu trabalho e na importância do sentido que este atribui ao gesto e do poder de influência sobre a sua própria actividade, pressupondo uma intervenção de prevenção que vise o restabelecimento dessa margem de manobra (Coutarel, Daniellou \& Dugué, 2005; Vézina, 2001) e que remeta para o processo de concepção da situação de trabalho.

6 Do estado actual das propostas de intervenção na prevenção das LME emergem três pontos a considerar (Coutarel, Daniellou \& Dugué, 2005) :

- a importância da articulação com as áreas da produção e da qualidade ; 
- os benefícios de um projecto participativo que inclua os trabalhadores e os responsáveis da empresa, ou seja, de uma intervenção que incida não só no meio técnico e organizacional mas também nos actores envolvidos e nas suas representações ;

- a necessidade de uma acção concertada baseada na compreensão da actividade, nas situações reais (ultrapassando o "fatalismo" associado a esta problemática e a ideia de que não é possível fazer de outra forma).

7 Uma intervenção deste tipo implica, assim, uma saída do "perímetro" tradicional das intervenções ergonómicas e uma neces- sidade de pluridisciplinaridade (Vézina, 2001). Esta evolução na forma de conceptualizar a temática implica a consideração de dimensões, por vezes negligenciadas, nomeadamente as dimensões i) cognitiva; ii) psicológica ; iii) organizacional e iv) económica (Bourgeois \& Hubault, 2005).

I. Um diagnóstico biomecânico das solicitações articulares e musculares nada diz acerca das intenções ou dos motivos que estão na origem dos gestos, já que estes revelam uma estratégia construída pela experiência. A actividade cognitiva faz do gesto um processo permanente de ajustamento dos seus modos operatórios, ou seja, a interpretação e a resposta do trabalhador determinam as características biomecânicas dos gestos e as consequências destes para a saúde.

II. gesto tem uma função psicológica fundamental, mobiliza recursos que permitem ao trabalhador fazer face aos constrangimentos, participando na construção da sua saúde. A prevenção das LME implica um modelo de análise que integre a dimensão psicológica do gesto para que se possa compreender o processo de alteração do mesmo.

III. A dependência versus autonomia organizacional influencia a prevalência das LME, na medida em que o trabalhador tem margem de manobra sobre a sua actividade (por exemplo a possibilidade de escolha dos tempos de pausa ou de variar o ritmo de trabalho). As mudanças tecnológicas e organizacionais reduziram certos aspectos penosos das situações de trabalho mas se umas recuam outras emergem (Cristofari, 2003), já que as exigências do mercado impõem novas necessidades (por exemplo séries de produção e prazos mais curtos, alterações frequentes de produção e de normas de qualidade), que podem comprometer precisamente a margem de manobra deixada ao trabalhador.

IV. Considera a dimensão do aporte de valor do trabalho para a empresa e pensa nos recursos mobilizados para uma determinada performance. É necessário sair da lógica taylorista (redução do gesto à sua dimensão mecânica e associação directa ao tempo e à produtividade) e pensar uma outra produtividade, não associada à execução de operações mas à realização de uma actividade complexa.

8 As propostas no âmbito da prevenção deste tipo de lesões po- dem, assim, ser enquadradas em duas grandes tendências ge- rais: intervenções i) focalizadas no trabalhador (ex: programas de melhoria da resistência e condição física dos trabalhadores) e intervenções ii) focalizadas na transformação das situações de trabalho. Partindo do princípio geral de que a intervenção ergonómica deve privilegiar não os efeitos de uma dada situação de trabalho mas antes a redução dos riscos que caracterizam essa situação, podemos enquadrar o trabalho apresentado neste artigo na segunda tendência.

\subsection{0 design centrado no utilizador : o conceito de design ergonómico}

9 Os princípios ergonómicos pressupõem uma orientação efectiva para as características bio-psico-sociológicas do trabalhador e é nesta linha que podemos conceber o design de 
situações de trabalho centrado no utilizador, enquanto compromisso (Das, Wimpee \& Das, 2002) entre as características dos trabalhadores e os requisitos da actividade e dos equipamentos.

As vantagens da consideração deste compromisso são reconhecidas na literatura (Bourgeois \& Hubault, 2005 ; Colombini, 1998 ; Coutarel, Daniellou \& Dugué, 2005 ; Vézina, 2001), bem como as consequências indesejadas (para o trabalhador e para a organização) do desvio a este compromisso, nomeadamente, a incidência de LME, os acidentes de trabalho e até mesmo a baixa produtividade. Mas apesar deste reconhecimento, o en- volvimento dos utilizadores tende a concentrar-se mais na avaliação de um determinado instrumento do que na sua concep- ção (McClelland, 1995). Embora os ergonomistas reforcem a importância de desenvolver métodos específicos que promovam a participação dos utilizadores no design, esta participa- ção nem sempre é considerada, em particular quando nos referimos ao design de máquinas ou instrumentos de trabalho no contexto industrial.

Este modelo misto de intervenção, que designamos de design participativo, baseia-se na participação democrática entre conceptores e utilizadores de um dado sistema (Lindgaard \& Caple, 2001), num processo cooperativo. O carácter participativo do processo permite oportunidades de conceber e alterar decisões que terão impacto no trabalho dos utilizadores finais (Muller, 1993), optimizando o seu desempenho e reduzindo as consequências negativas já enunciadas.

Béguin \& Duarte (2008) reforçaram já a importância da participação dos utilizadores finais no que concerne à concepção e/ou implementação de situações de trabalho (quer se trate de espaços de trabalho, processos produtivos, utensílios, interfaces, softwares, etc.) Esta abordagem parte do reconhecimento da contribuição criativa dos utilizadores (Béguin, 2008) e da necessária reinterpretação que estes fazem das mudanças. $O$ autor coloca a ênfase no "lugar do trabalho e dos trabalhadores" na condução de um projecto de concepção ou mudança. Duarte, Conceição, Cordeiro \& Lima (2008) referem ainda a necessidade de um "diálogo entre conceptores e utilizadores "e um diálogo com a própria situação, que se concretiza num processo cíclico. Béguin (2008) chama-lhe mesmo o "processo dialógico da concepção", integrando uma dimensão temporal. Para o autor, a concepção não é uma fase inicial de um projecto, que antecede a sua execução, mas é um contínuo que se estende para lá da implementação e que continua durante o uso.

13 Esta posição revela um certo posicionamento teórico e epistemológico, nomeadamente no que respeita à relação entre conhecimento e acção. Se por um lado é necessário um input inicial com base em conhecimentos construídos e comprovados (como o conhecimento técnico dos engenheiros, o conhecimento científico dos ergonomistas e conceptores), por outro lado, é sobre esta base que se definem produtos, mudanças, transformações e inovações. Isto significa que "a efectivação da acção em situação, o uso de uma novidade técnica produz um conhecimento novo que não é completamente possível de identificar a priori, pelo que se torna necessário construir interfaces entre conceptores e operadores que articulem a construção de saberes e a elaboração da aç̧ão" (Béguin \& Duarte, 2008, p. 13). 


\subsection{0 processo participativo : do conhecimento à acção}

\section{desenvolvida nesta situação de trabalho, os procedimentos metodológicos adoptados no} terreno e os principais resultados obtidos.

\section{Descrição do caso} de transformadores em grande escala. A actividade analisada é a de concepção de bobines, que constituem uma componente essencial para cada um dos produtos finais.

tarefas completamente distintas : barra ; banda. A camada de AT também pode assumir dois tipos, sendo que nestes casos há semelhanças no que diz respeito aos procedimentos: AT de barra ou fio grosso; AT de fio médio ou fio fino. Todos estes materiais são de cobre, rápido condutor da corrente eléctrica.

Estes 4 tipos de camadas são feitos em 4 tipos de máquinas diferentes, sendo que as máquinas que produzem camadas AT dependem da bobinagem de Baixa Tensão (BT). No total, existem 11 máquinas : 2 BT banda ; 2 BT barra ; 2 AT barra ou fio grosso ; 5 AT fio médio ou fio fino. 
Genericamente a concepção de bobines AT, divide-se em 3 grandes tarefas, que por sua vez se subdividem em sub-tarefas, conforme ilustra a tabela e a figura seguintes :

Figura 1: llustração do transformador e da concepção da bobine

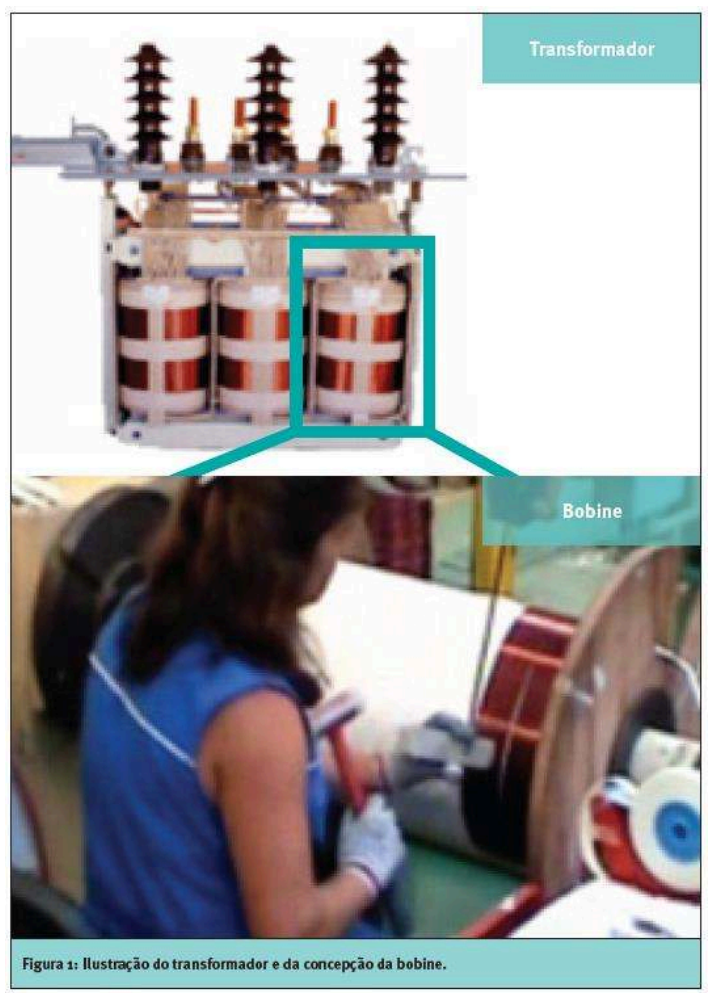

O processo produtivo inicia-se com a colocação das bobines BT nas máquinas de bobinagem (Preparação e colocação da bobi- ne na máquina). 0 processo de Bobinagem consiste maiorita- riamente no enrolamento do fio, em várias camadas, sendo que um dos requisitos é que o fio seja enrolado com o mínimo de folgas possível. Entre cada camada, normalmente coloca-se um material isolante (isolamento), que evita o sobreaquecimento (e consequente curto-circuito) do transformador. A colocação de tiras, quando é necessária, é feita duas vezes por camada, nas extremidades da bobine ; a colocação das tomadas exige por vezes um processo de soldadura entre as pontas do fio de cobre ; colocar canais nas bobines é um processo raro, que implica muito pouco tempo dispendido. Quando a bobine está pronta, os operadores têm ainda que as retirar da máquina, sendo este um processo relativamente rápido. A tarefa de Bobinagem é, assim, a que mais ocupa os operadores, sendo que o Enrolamento do fio é a sub-tarefa que mais tempo exige. Relativamente aos aspectos organizacionais mais relevantes, estes postos de trabalho funcionam com 2 turnos de 8 horas cada. No que diz respeito às pausas, existe uma pausa oficial havendo margem de manobra para serem efectuadas mais pausas, em função da necessidade dos trabalhadores. A amos- tra de trabalhadores envolvidos é maioritariamente feminina (e exclusivamente feminina na bobinagem AT), com antiguidade elevada na empresa e vínculos de trabalho sem termo. A formação técnica decorreu, em geral, através da aprendizagem pela prática junto de colaboradores mais experientes na função. 
Tabela 1: Tarefas e sub-tarefas para a concepção de bobines de Alta Tensão

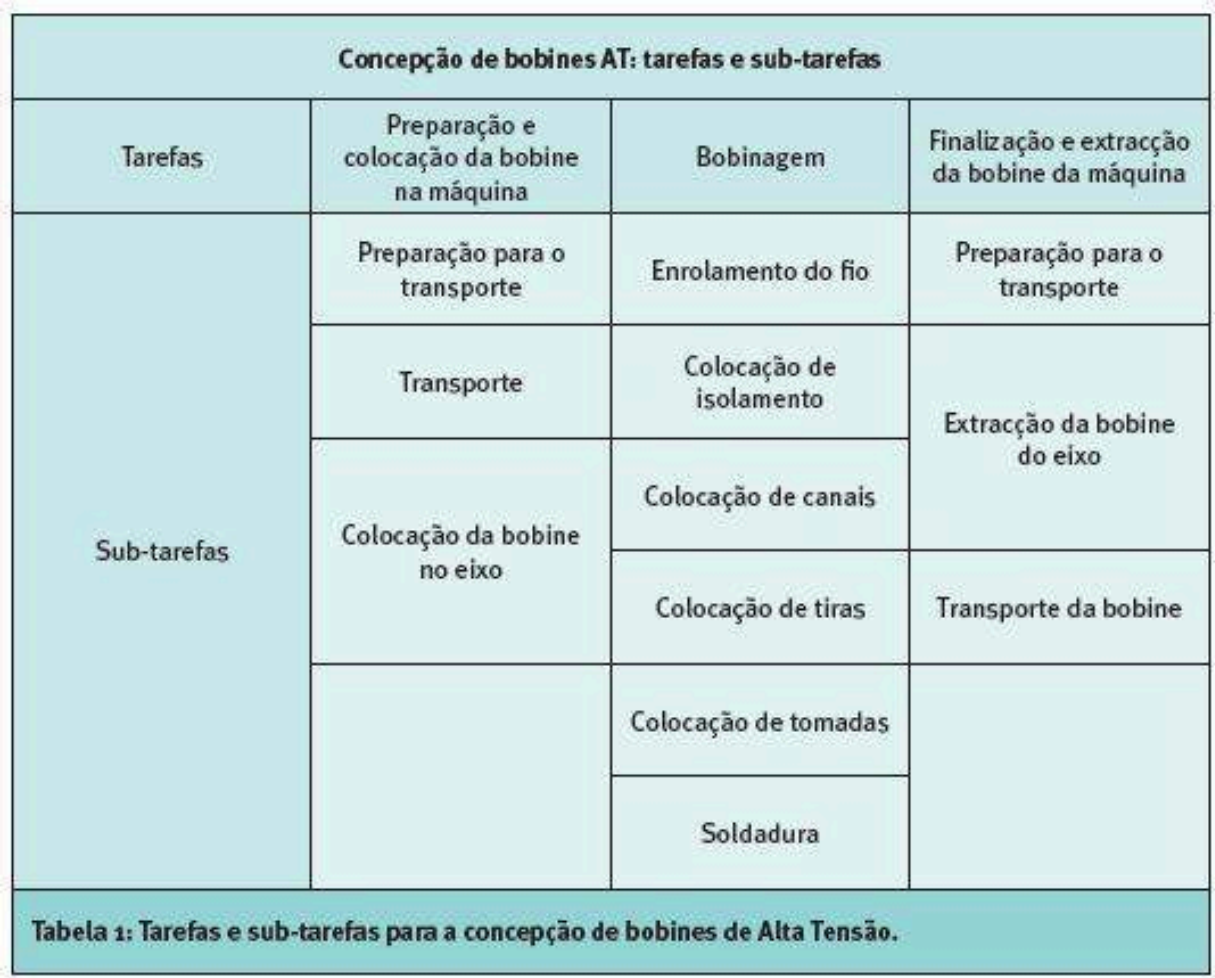

Figura 2: Tarefas da concepção de bobines AT

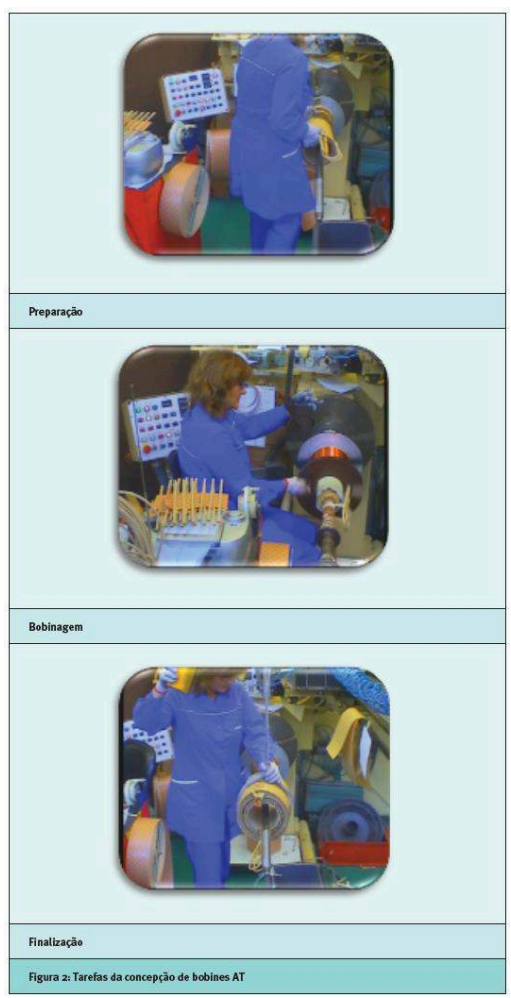




\section{Metodologia}

\subsection{Fase 1 - Análise e reformulação do pedido}

27 Esta primeira fase correspondeu à análise e reformulação do pedido que foi dirigido è equipa e compreendeu a análise da actividade dos trabalhadores envolvidos. Ao nível dos procedimentos, recorremos à análise documental (processo produtivo, descrição de máquinas, normas internas, etc.) e a reuniões informais com diferentes actores organizacionais, nomeadamente, os responsáveis pela segurança e pela produção, o médico do trabalho e os próprios trabalhadores. Procedeu-se ainda a observações livres nos diferentes postos de trabalho, as quais decorreram durante os $1^{\circ}$ e $2^{\circ}$ turnos e envolveram os 16 trabalhadores distribuídos pelos 11 postos de trabalho. Em simultâneo, foram sendo colocadas algumas questões que nos ajudaram a esclarecer as dúvidas que surgiam inerentes aos processos de trabalho adoptados.

No que diz respeito à caracterização dos trabalhadores envolvidos neste estudo, podemos caracterizar dois grupos, os quais designámos de amostra 1 e 2 . A amostra 1 corresponde à população total dos postos de trabalho de bobinagem, contem- plando 16 trabalhadores, entre os quais 6 são do género masculino e os restantes 10 do género feminino. A maioria destes operadores situa-se na faixa etária dos 31 aos 50 anos, sendo que a sua experiência na bobinagem é maioritariamente entre os 11 e os 20 anos. A amostra 2 corresponde a uma fracção da amostra 1 , mais especificamente às operadoras que concebem bobines do tipo AT, sendo na totalidade 9, todas do género feminino. No que diz respeito à faixa etária e aos anos de experiência na bobinagem, são muito semelhantes às da amostra 1 . Os objectivos desta fase foram, essencialmente conhecer os diferentes tipos de tarefas associados a todo o procedimento de bobinagem, contextualizá-los na problemática em causa e, consequentemente, fazer o despiste daquelas que poderiam ser as situações mais críticas de todo o processo. Foi neste sentido que foram utilizados instrumentos mais sistemáticos e focalizados, em função das primeiras necessidades identificadas na situação.

\subsubsection{Questionário}

O questionário teve como objectivos : identificar as regiões corporais mais afectadas, bem como os sintomas mais frequentemente associados; identificar factores de risco desencadeadores dos sintomas anteriormente referidos; fazer o despiste em relação às máquinas e/ou bobines mais problemáticas.

30 Esta ferramenta foi elaborada com base nos resultados das observações livres e das entrevistas informais, estando estruturada em duas grandes partes : (1) questionário de sintomas ; (2) questionário geral do posto de trabalho.

31 O questionário geral do posto de trabalho (2) englobava um vasto leque de questões relacionadas com : acidentes ou incidentes de trabalho ocorridos até então ; postura de trabalho; elementos físicos que compõem o posto de trabalho (ex. : cadeira, monitor, painel, etc.) ; ferramentas de ajuda utilizadas para a realização da actividade ; utilização de equipamentos de protecção individual (EPI's); tipo de bobines concebidas; máquinas utilizadas para a concepção das bobines; turnos de trabalho; pausas efectuadas; produtividade dos operadores; realização de horas extraordinárias; 
execução de outras tarefas que não as de bobinagem ; estratificação da amostra (ex. : idade e género).

Este instrumento foi aplicado, sob a forma de entrevista, a todos os operadores da bobinagem (amostra 1). Para que as respostas se reportassem o mais possível à realidade de trabalho, procedemos à aplicação do questionário no próprio local de trabalho durante a actividade dos trabalhadores. É de referir que esta opção teve em consideração a natureza e o ritmo da actividade, para que a administração dos instrumentos não prejudicasse o desempenho/segurança.

\subsubsection{OCRA checklist e HAL}

Estas duas ferramentas estão agrupadas no mesmo ponto, uma vez que a sua aplicação teve um objectivo comum: fazer o despiste da tarefa mais problemática para os trabalhadores, no que respeita ao risco de desenvolvimento de LME nos membros superiores.

O objectivo da aplicação do OCRA (Occupational Repetitive Actions) foi identificar as tarefas de risco mais elevado. O índice OCRA teve origem na necessidade de integração da avaliação dos principais factores de risco (repetitividade, força, postura, ausência de períodos de recuperação e outros factores adicionais como por exemplo as vibrações) utilizando métodos de quantificação (Occhipinti, 1998 ; Colombini, 1998; Occhipinti \& Colombini, 2007 ; Occhipinti, Colombini \& Occhipinti, 2008). Neste instrumento a aç̧ão técnica é identificada como variável característica a considerar para os movimentos repetitivos dos membros superiores (Serranheira, 2007). Esta acção é poste- riormente transformada em factores quantificados através da frequência relativa numa determinada unidade de tempo, de onde resulta um índice de exposição (aceitável, baixo, modera- do ou elevado)

Com a aplicação do HAL (Hand Activity Level), pretendeu-se determinar se a actividade analisada envolvia risco de LME para os membros superiores distais. O HAL (Lakto et al., 1997) é um método de avaliação da exposição em actividades manuais, especificamente orientado para as extremidades distais do mem- bro superior (antebraço, punho e mão). Este instrumento pre- tende avaliar o nível de actividade manual e o de aplicação de força em postos de trabalhos (Serranheira, 2007), baseado na frequência da actividade manual durante o ciclo de trabalho. As tarefas analisadas e comparadas, referentes às bobines do tipo AT, foram: i) Preparação e colocação da bobine na máquina ; ii) Bobinagem ; iii) Finalização e extracção da bobine da máquina (cf. tabela 1 e figura 2). As operadoras em análise concebiam bobines diferentes entre si (bobine 1, 2 e 3), nomeadamente no que diz respeito à espessura do fio enrolado, o que determina modos operatórios diferentes.

Para a aplicação destes instrumentos, foi filmada a actividade de três operadoras durante a execução de bobines do tipo AT (ou seja, pertencentes à amostra 2). Quer o OCRA quer o HAL foram aplicados com recurso aos vídeos, por dois analistas, de modo a controlar a consistência inter-analista e a garantir a fia- bilidade dos resultados.

\subsubsection{RULA e Strain Index (SI)}

37 À semelhança das ferramentas referidas anteriormente, estas duas encontram-se igualmente associadas, já que a sua aplica- ção conjunta permitiu identificar as 3 sub- 
tarefas mais penosas para as operadoras da tarefa de Bobinagem (bobines do tipo AT), no leque das 6 sub-tarefas que fazem parte da bobina- gem (bobines do tipo AT).

Especificamente, o objectivo da aplicação do RULA (Rappid Upper Limb Assessment) foi classificar o risco de LME no membro superior relacionadas com as sub-tarefas em análise, essencial- mente com base no factor postura. Com a aplicação do SI, pretendeuse igualmente uma classificação do risco de LME no membro superior associado a essas sub-tarefas, tendo em conta outro tipo de variáveis (intensidade, repetitividade, duração, etc.).

No que diz respeito à selecção dos instrumentos, optámos por utilizar o OCRA checklist e o HAL numa primeira abordagem, por serem mais genéricos, sendo que as suas questões não reportavam à especificidade de uma situação mais concreta, como acontece com o RULA e o SI. Estes dois últimos instrumentos referem-se a uma postura ou a um movimento específicos.

O RULA destina-se à avaliação das posturas no local de traba- lho (McAtamney \& Corlett, 1993), considerando a força exercida, as acções musculares dinâmicas e estáticas e a repetitividade, abrangendo dois grupos de regiões corporais (Grupo A : membros superiores e Grupo B : região cervical, dorso-lombar e membros inferiores).

O SI consiste num método semiquantitativo de avaliação do ín- dice de esforço, uma vez que o resultado se traduz num dado numérico qualitativo (Serranheira, 2007). Este método foi desenvolvido a partir do conhecimento fisiológico e biomecânico (Moore \& Garg, 1995) e pretende indicar o nível de risco, englobando a medição da intensidade, duração e frequência do esforço, bem como a postura da mão/punho, a velocidade e a duração da tarefa.

À semelhança dos instrumentos anteriores, também estes foram aplicadas com recurso às filmagens captadas anteriormente, pelos mesmos dois analistas.

43 As sub-tarefas em análise, da tarefa Bobinagem, foram as seguintes : i) Enrolamento do fio ; ii) Colocação do isolamento ; iii) Colocação de canais ; iv) Colocação de tiras ; v) Colocação de tomadas ; vi) Soldadura (cf. tabela 1 e figura 3 ). 
Figura 3: Sub-tarefas da bobinagem

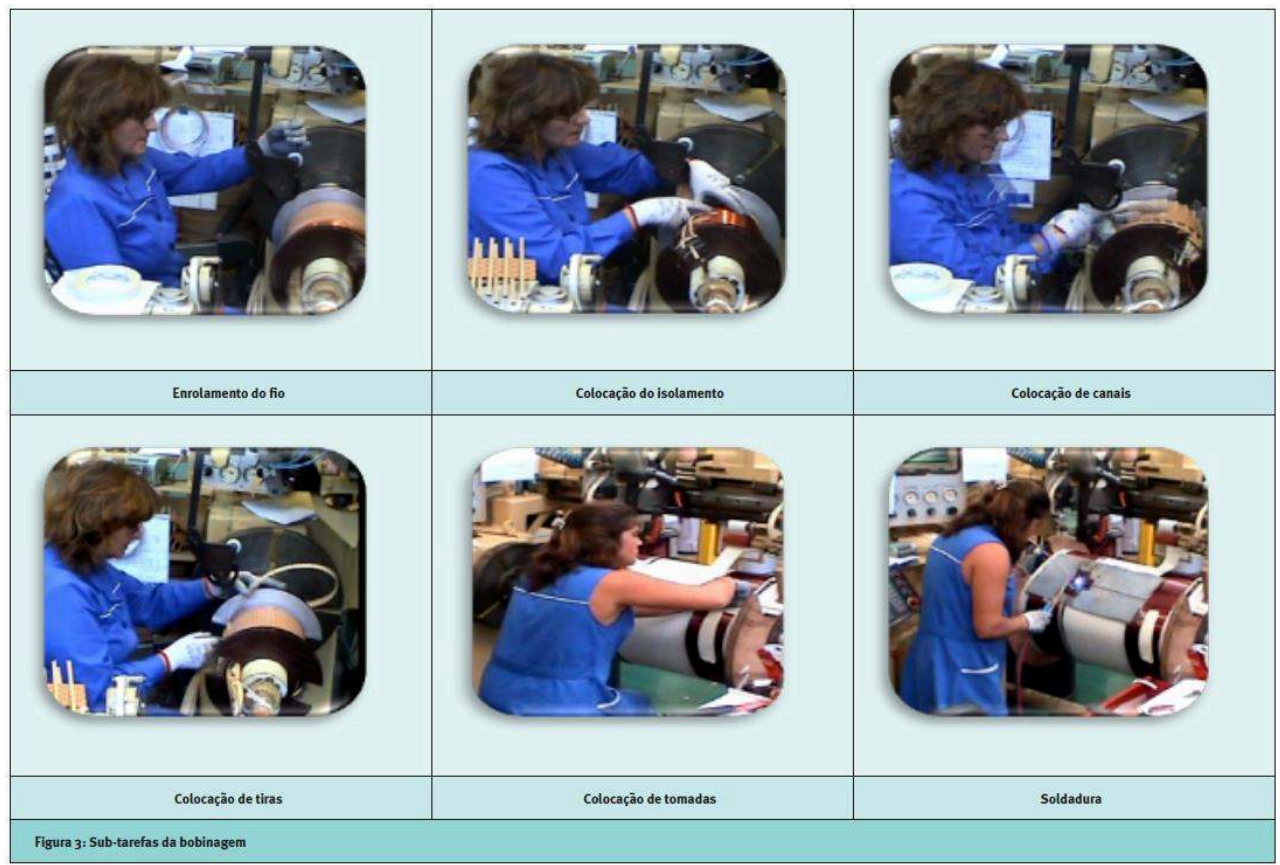

\subsubsection{Behaviour Vídeo}

Depois de identificadas as sub-tarefas mais problemáticas, tornou-se necessário aprofundar mais a análise, de modo a concretizar quais os comportamentos dessas subtarefas poderiam estar na origem das queixas e sintomas das operadoras. Para este efeito recorreu-se ao Behaviour Vídeo (Filgueiras \& Rebelo, 2007). Genericamente, esta é uma aplicação que contabiliza o número de vezes que uma operadora executa um determinado comportamento, bem como a sua duração parcial e total, durante um ciclo de trabalho.

Mais uma vez, e inevitavelmente, recorremos aos registos de vídeo para proceder à aplicação desta ferramenta. Pela sua exigência temporal de análise (o dobro do tempo em relação ao tempo real de cada vídeo), o Behaviour Vídeo foi aplicado ape- nas por um especialista e, posteriormente analisado pela equipa de trabalho.

Foram analisados 6 comportamentos diferentes por sub-tarefa, o que perfez um total de 18 comportamentos por vídeo, cuja especificação se encontra na tabela seguinte : 
Tabela 2. Comportamentos analisados na ferramenta Behaviour Vídeo

\begin{tabular}{|c|c|c|c|c|}
\hline \multicolumn{5}{|c|}{ Comportamentos analisados no BehaviourVideo } \\
\hline Bobines (AT) & $1,2,3$ & 2 & 1,3 & $1,2,3$ \\
\hline Sub-tarefa & Enrolamento do fio & $\begin{array}{c}\text { Colocação do } \\
\text { isolamento }\end{array}$ & Colocação de tiras & $\begin{array}{c}\text { Colocaçăo de } \\
\text { tomadas }\end{array}$ \\
\hline \multirow{6}{*}{ Comportamentos } & Regular a máquina & Regular a máquina & Regular a máquina & Regular a máquina \\
\hline & $\begin{array}{l}\text { Encostar o fio } \\
\text { (por baixo) }\end{array}$ & Puxar interno & Puxar interno & Puxar interno \\
\hline & $\begin{array}{l}\text { Encostar o fio } \\
\text { (por cima) }\end{array}$ & Puxar externo & Puxar externo & Puxar externo \\
\hline & Bater no fio & Colar & Colar & Colar \\
\hline & Segurar o fio & Cortar & Cortar & Cortar \\
\hline & $\begin{array}{l}\text { Acompanhar o } \\
\text { enrolamento }\end{array}$ & $\begin{array}{l}\text { Segurar no isola- } \\
\text { mento }\end{array}$ & $\begin{array}{l}\text { Encostar e bater } \\
\text { na tira }\end{array}$ & Bater na tomada \\
\hline
\end{tabular}

\subsection{Fase 2 - Primeira análise dos resultados}

Na segunda fase, procedeu-se à elaboração de uma primeira análise dos resultados, a qual foi alvo de discussão contínua no seio da equipa (ergonomistas, psicólogo do trabalho, médico do trabalho e engenheiros da manutenção, produção e segurança). No seguimento destas duas primeiras fases, foi possível identificar as seguintes conclusões :

I. os operadores com maior número de queixas produzem bobines de alta tensão (AT) ;

II. as regiões corporais mais afectadas são: punho direito, região lombar, zona cervical, mão direita ;

III. na mão direita, os operadores queixam-se sobretudo nas zonas dos dedos polegar, indicador e médio ;

IV. do ponto de vista dos utilizadores, as razões pelas quais ocorrem estes sintomas devem-se a vários comportamen- tos que estes adoptam durante a actividade (como encostar o fio ou bater no fio durante o seu enrolamento), atribuindo também à postura um factor de risco para o desenvolvimento de LME.

Depois de percebermos que os postos de trabalho mais problemáticos eram os de concepção de bobines do tipo AT, procede- mos à aplicação dos instrumentos OCRA e HAL, tendo sido analisadas as três grandes tarefas do processo de bobinagem.

Relativamente aos resultados do OCRA, concluímos que nos vários postos de trabalho analisados (produção de bobines AT) a tarefa Bobinagem é a mais problemática, obtendo-se sempre valores correspondentes a um elevado risco de ocorrência de LME. Também através do HAL se confirmou que a tarefa mais problemática é a Bobinagem, sendo que a mão direita apresentou valores de risco mais elevados. 
51 Deste modo, restringimos a nossa análise para as sub-tarefas da tarefa até então considerada mais problemática. Através das ferra- mentas RULA e Strain Índex (SI) verificou-se que a sub-tarefa "enrolamento do fio" é a mais penosa (RULA $\approx 7$ ), seguida da "colocação de tomadas" (RULA $\approx 5,5$ ), para os 3 tipos de bobines. Houve, no entanto, algumas sub-tarefas que não obtiveram consenso : a "colocação de tiras" (RULA $\approx 7$ ) teve um valor bastante significativo apenas na bobine do tipo 2 ; a "colocação de tiras" $($ RULA $\approx 4)$ foi a $3^{\text {a }}$ sub-tarefa mais problemática nas bobines do tipo 1 e 3 .

Relativamente aos resultados do SI, mais uma vez se verificou claramente o maior nível de risco de LME nos membros supe- riores do lado direito.

53 Após a decomposição de cada uma destas sub-tarefas em comportamentos, procedemos à sua análise detalhada, quer do número de ocorrências, quer do tempo total de exposição às respectivas posturas, por ciclo de trabalho.

54 Concluiu-se que, no que diz respeito à frequência relativa dos comportamentos (cf. figura 4), os mais significativos são :

I. Regular a máquina, caracterizado por uma postura de tor- ção do tronco à esquerda, e utilização dos dedos da mão da esquerda para premir os botões, com o respectivo membro superior suspenso ;

II. Puxar externo, que corresponde ao acto de puxar todos os elementos que estejam externos à máquina, nomeadamen- te a fita adesiva. Neste caso, acontece que para além da repetitividade deste comportamento é necessária alguma força para cortar a fita, implicando assim um esforço acres- cido na zona da mão que faz a pega em pinça (dedos pole- gar, indicador e médio);

III. Colar (a fita adesiva), estando bastante associado ao tópico anterior. Neste comportamento, os operadores utilizam ou o dedo indicador ou o polegar (acrescendo desta forma o esforço diário nestas zonas) ;

IV. Bater no fio, normalmente utilizado em alternativa à vare- ta (usada para encostar o fio). Este comportamento é ca- racterizado pela utilização de um maço sobre a bobine, com a mão direita.

Quanto à duração relativa dos comportamentos, verificou-se que os mais presentes ao longo do turno, são :

I. Encostar o fio (nomeadamente por baixo), que implica a utilização de uma vareta de madeira para encostar o fio na bobine, bem como a aplicação de uma força considerável para a sua eficácia. Para tal, o operador fica sujeito às vibrações decorrentes do enrolamento do fio, sendo que a mão mais utilizada para segurar na vareta, é a direita ;

II. Bater no fio ;

III. Regular a máquina. 
Figura 4: Comportamentos críticos

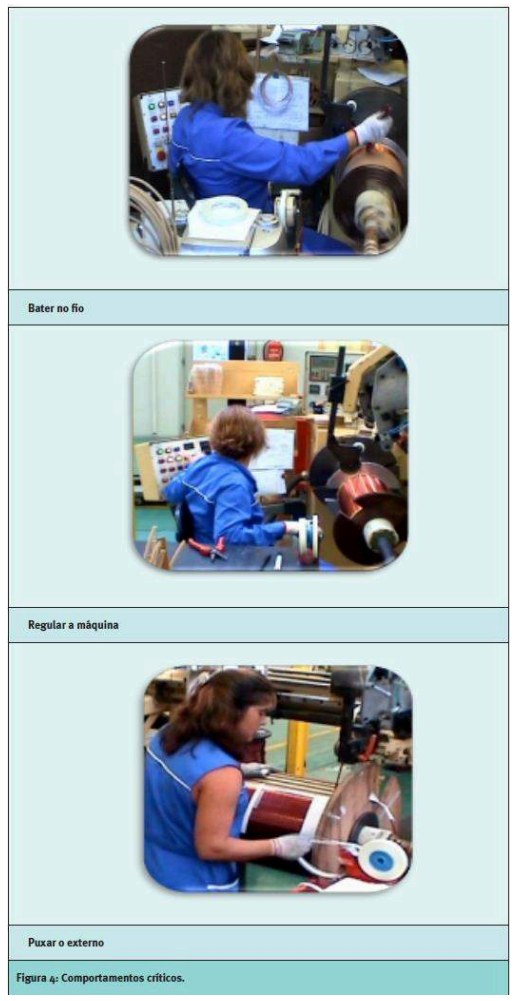

Como culminar desta $2^{\mathrm{a}}$ fase, foi preparada uma síntese destes resultados, a qual foi apresentada à Direcção da empresa e discutida por toda a equipa. Este foi um momento importante para o processo, pelo resultante envolvimento das chefias. Os trabalhadores acompanharam sempre todo o trabalho efectuado e tiveram igualmente conhecimento desta sessão, o que contribuiu para o reforço da sua participação. Aliás, para promovermos este envolvimento contínuo, a equipa preparou um conjunto de materiais de divulgação que incluía os principais resultados da análise e fases futuras da intervenção a ser difundido no circuito interno de vídeo da empresa.

\subsection{Fase 3 - As propostas de transformação}

Os resultados descritos na secção anterior revelaram a necessidade de uma intervenção de reconcepção desta situação de trabalho. Neste sentido, foram concebidas algumas propostas de intervenção no posto de trabalho mais problemático.

Em termos gerais, a intervenção proposta focou-se em três aspectos da interacção dos trabalhadores com o sistema que se revelaram problemáticos :

I. Substituição do dispositivo existente para a realização do "puxar externo" por um dispositivo automático dispensador de fitas ;

II. Alteração do dispositivo de controlo da máquina que implica duas intervenções: a) a transferência da função de regu- lação da máquina existente no painel de controlo para um dispositivo manual situado junto à mão do operador, o qual permite maior precisão da regulação e, ao mesmo tempo, reduz as acções de "bater no fio", "encostar o fio" e "regu- lar a máquina" (evitando o uso da vareta) ; e b) a alteração do braço da máquina para tensionar o fio e permitir um ajus- tamento mais adequado ao tipo de bobine em execução. 
III. Transformação do próprio posto de trabalho, em particular a configuração e posicionamento do pedal de controlo da máquina e a cadeira utilizada pelos trabalhadores, no sen- tido de melhorar a interacção com a máquina.

59 Estas propostas resultaram de um processo de reflexão con- junta por parte da equipa, desenvolvida em várias reuniões de discussão colectiva. Neste processo foi importante a participa- ção de outros actores, nomeadamente técnicos e fornecedores de máquinas que se envolveram na concepção de algumas das transformações (em particular a referida em ii). Um dos ele- mentos determinantes nesta fase foi a participação dos traba- lhadores, os quais acompanharam os momentos em que os engenheiros e os técnicos observaram as máquinas (juntamen- te com a restante equipa) e exploraram as possibilidades de alteração, tendo estas sido continuamente discutidas e valida- das junto dos trabalhadores.

\subsection{Fase 4 - Implementação da mudança}

Esta fase corresponde à introdução das propostas anteriormente descritas na situação de trabalho, um processo moroso e que ainda se encontra em curso.

Relativamente ao dispensador de fitas (i), uma das discussões da equipa pluridisciplinar deste projecto, centrou-se na sua localização, uma vez que não podia interferir com a realização da actividade de cada operadora e, por outro lado, deveria estar num espaço óptimo de alcance, considerando a elevada frequência de uso deste dispositivo. Para além disto, o requisito a considerar era que para o seu uso adequado, a operadora necessitava de puxar a fita adesiva (ou com os dedos da mão esquerda ou com os da direita). Neste sentido, sugeriu-se a introdução de um braço na máquina articulado e amovível, à direita das operadoras, para colocar o dispensador.

No que diz respeito ao dispositivo manual de regulação da distância da queda do fio (ii), questionámo-nos inicialmente sobre o tipo a ser adoptado, pelo que averiguámos que o melhor seria optar por uma espécie de joystick bilateral, com dois sensores de activação por pressão : um de cada lado. Deste modo, ao serem activados, deverão emitir feedback cinestésico e visual, de modo às operadoras percepcionarem a sua actividade. Tendo em conta que o objectivo da alteração desta funcionalidade, era minimizar a ocorrência de pelo menos três comportamentos de risco (essencialmente pela sua repetitividade e duração), prevê-se que esta passará a ser uma "ferramenta" de utilização constante. Desta forma, deverá estar localizada no prolongamento do antebraço de cada operadora, sem que seja exigida a adopção de posturas de risco. Tendo em conta que existe uma cadeira no posto de trabalho, com possibilidade de ter um apoia-braços, a nossa proposta surgiu no sentido de se colocar o joystick no prolongamento do apoiabraços, dando a hipótese a cada utilizadora de o colocar no lado direito ou esquerdo. Uma das grandes vantagens associadas a este mecanismo consiste em permitir que as operadoras passem a ter a percepção directa de que a acção que executam (para a esquerda ou para a direita) se traduz numa reacção da máquina/fio também ela para a esquerda ou para a direita, respectivamente.

63 Conforme seria de esperar, todas estas alterações dependem umas das outras, havendo desta forma necessidade de se estabelecerem relações constantes de compromisso. As questões relacionadas com a altura do posto de trabalho, e com a cadeira (iii) não foram excepção. As cadeiras actualmente existentes não permitem regulação de altura e não têm apoio-lombar (tendo apenas um dorsal), que se traduz na adopção de posturas 
desfavoráveis, como por exemplo o facto de as operadoras estarem chegadas à frente para estarem com os pés adequadamente no chão (devido à necessidade de uso de um pedal). Com efeito, e face à variação morfológica e dimensional entre os diferentes trabalhadores, sugeriu-se a aquisição de cadeiras adequadas, cuja variação de altura de assento fosse acompanhada da variação de altura de um apoia-pés, obviamente com o pedal por cima deste. Desta forma, acreditamos que as operadoras passarão a adoptar posturas mais confortáveis, nomeadamente porque passarão a olhar para a bobine pelo ângulo que pretenderem e que mais convier a cada uma, passando também a utilizar os apoios das costas (tendo sido sugeridos os lombar e dorsal).

No que concerne às mudanças já efectuadas [1] e considerando as três principais propostas de intervenção, o estado actual de implementação é o seguinte :

I. Quanto ao dispensador de fitas foi implementado um dispensador automático de fitas précortadas em todas as máquinas do sector da bobinagem, tendo sido negociada com os trabalhadores e com os engenheiros a localização específica do dispensador ;

II. No que respeita à alteração do dispositivo de controlo da máquina, ambas as alterações propostas foram efectuadas apenas numa das máquinas, a qual será usada para testar as transformações e para que os trabalhadores possam experimentar estas mudanças e sugerir eventuais reformulações antes que estas sejam disseminadas pelas restantes máquinas ;

III. As mudanças propostas ao nível da transformação do próprio posto de trabalho não foram ainda concretizadas devido a constrangimentos organizacionais (nomeadamente económicos devido à diminuição da produção no sector da bobinagem, o qual se encontra actualmente em "layoff" ou "paragem técnica" por tempo ainda não determinado).

65 À semelhança do que aconteceu ao longo de todo o estudo, a equipa acompanhou esta fase e garantiu a participação dos trabalhadores. Exemplos desta participação foi o processo de negociação para a selecção da tipologia de cadeiras mais adequadas ao posto de trabalho, onde todos os trabalhadores foRam ouvidos dando o seu contributo para a escolha. Outro exemplo foi a possibilidade de experimentarem as mudanças que iam sendo efectuadas num dos postos de trabalho que serviu de "posto piloto" para que a engenharia procedesse às intervenções necessárias.

\section{Conclusão}

A abordagem para os problemas músculo-esqueléticos tem consistido na implementação de medidas focalizadas no próprio trabalhador (como é o caso da ginástica laboral) ou medidas organizacionais, como a introdução de pausas, rotação dos trabalhadores ou adopção de estratégias de polivalência (afastando temporariamente o operador da situação nociva). No entanto, e apesar dos benefícios que tais medidas possam ter do ponto de vista do bem-estar do trabalhador, permanecemos sempre numa gestão efectuada no plano das consequências da exposição ou do tempo de exposição e não numa gestão do risco orientada para a prevenção.

Esta intervenção procura abordar os problemas músculo-esqueléticos em relação profunda com a actividade, enquanto reveladores de um disfuncionamento na interacção do operador com os dispositivos de controlo. Ao concebermos os problemas músculo-esqueléticos como estando associados aos processos cognitivos envolvidos na realização da actividade, conduzimos a nossa intervenção para a mudança da própria situação de trabalho. Esta preocupação é particularmente evidente na proposta de 
alteração do dispositivo de controlo da máquina (ii), onde se procura deslocar e transformar uma função nobre do painel de controlo para permitir o acesso e uso mais facilitado às operadoras, alterando de forma profunda a relação estabelecida com o dispositivo e as operações mentais envolvidas na actividade.

É ainda de realçar o contínuo envolvimento dos elementos da equipa, em particular das operadoras dos postos de trabalho envolvidos nas transformações propostas, em todas as fases do processo. A criação de um posto de trabalho "piloto" no qual os trabalhadores têm oportunidade de experimentar as mudanças e contribuir para o sucessivo desenvolvimento das mesmas constitui, sem dúvida, uma forma de concretizar a participação destas e de estender a sua participação à fase de implementação. Este processo permitiu-nos compreender a importância do "diálogo entre conceptores e utilizadores" e do "diálogo com a situação", defendido por Duarte, Conceição, Cordeiro \& Lima (2008). É neste diálogo que a reconcepção adquire sentido, é reinterpretada pelos diversos actores e apropriada pelos utilizadores finais, contribuindo para uma melhoria efectiva das situações de trabalho.

\section{BIBLIOGRAFIA}

Bourgeois, F. \& Hubault, F. (2005). Prévenir les TMS. De la biomécanique à la revalorisation du travail, l'analyse du geste dans toutes ses dimensions. @ctivités, 2, 1, 1936, http://www. activites.org/v2n1/bourgeois.pdf

Colombini, D. (1998). An observational method for classifying exposure to repetitive movements of the upper limbs. Ergonomics, 41, (9), 1261-1289.

Colombini, D. \& Occhipinti, E. (2006). Preventing upper limb work-related musculoskeletal disorders (ULWMSDS) : New approaches in job (re)design and current trends in standardization. Applied Ergonomics, 37, 441-450.

Coutarel, F., Daniellou, F. \& Dugué, B. (2005). La prévention des troubles musculo-squelettiques : quelques enjeux épistémologiques. @ctivités, 2, 1, 3-18, http://www.activites.org/v2n1/ coutarel.pdf Cristofari, M.-F. (2003). Bilan de sources quantitatives dans le champ de la santé et de l'itinéraire professionnel. CEE 03/11, http://www.ceerecherche.fr

Béguin, P. (2008). Argumentos para uma abordagem dialógica da inovação. Laboreal, 4, (2), 72-82. http://laboreal.up.pt/revista/ artigo.php ?id =37t45nSU547112341787:352:81

Béguin, P.\& Duarte, F. (2008). Ainovação : entreotrabalhodosprojetistas e o trabalho dos operadores. Laboreal, 4, (2), 10-14. http://laboreal. up.pt/revista/artigo.php ?

id $=37$ t45nSU5471123417879622:21

Das, B., Wimpee, J. \& Das, B. (2002). Ergonomics evaluation and redesign of a hospital meal cart. Applied Ergonomics, 33, 309-318.

Duarte, E., \& Rebelo, F. (2004). Compreensão da sinalética. Serão os sinais de segurança compreendidos? Comunicação apresentada em Interacção 2004 - I Conferência Nacional em Interacção PessoaComputador., Faculdade de Ciências da Universidade de Lisboa, 12-14 de Junho. 
Duarte, F., Conceição, C., Cordeiro, C. \& Lima, F. (2008). A integração das necessidades de usuários e projetistas como fonte de inovação para o projecto. Laboreal, 4, (2), 59-71. http://laboreal. up.pt/ revista/artigo.php ?id =48u56oTV658223452898;343;82

Filgueiras, E. \& Rebelo, F. (2007). An Interactive System to Measure the Human Behaviour : An Analysis Model for the Human-Product- Environment Interaction. Ergonomics and Health Aspects of Work with Computers. Proceedings of the International Conference, EHAWC 2007, Held as Part of HCI International 2007, Beijing, China, July 22-27, vol. 4566/2007, 199-206.

Lakto, W., Armstrong, T., Foulke, J., Herrin, G., Rabourn, R. \& Ulin, S. (1997). Development and evaluation of an observational method for assessing repetition in hand tasks. American Industrial Hygiene Association Journal, 58, 4, 278-285.

Lindgaard, G. \& Caple, D. (2001). A case study in iteractive keybord design using participatory design techniques. Applied Ergonomics, 32, 71-80.

Looze, M., Urlings, I., Vink, P., van Rhijn, J., Miedema, M., Bronkhorst, R. \& van der Grinten, M. (2001). Towards successful physical stress reducing products : an evaluation of seven cases. Applied Ergonomics, 32, 525-534.

McAtamney, L. \& Corlett, E. (1993). RULA -Rappid Upper Limb Assessment : a survey method for the investigation of work- related upper limb disorders. Applied Ergonomics, 24, 2, 91-99.

McClelland, I. (1995). Product assessment and user trials. In J.R. Wilson \& E.N. Corlett (Eds.). Evaluation of Human Work : a practical ergonomics methodology. London : Taylor and Francis.

Muller, M. (1993). Pictive : democratizing the dynamics of the design session. In D. Schuler \& A. Namioka (Eds.). Participatory Design : principles and practices. Hillsdale : Lawrence Erlbaum Associates. Moore, J. \& Garg, A. (1995). The Strain Index : a proposed method to analyse jobs for risk of distal upper extremity disorders. AmericanIndustrial Hygiene Association Journal, 56, 443-458.

Occhipinti E. (1998). OCRA - a concise index for the assessment of exposure to repetitive movements of the upper limbs. Ergonomics, 41, (9), 1290-1311.

Occhipinti, E. \& Colombini D. (2007). Updating reference values and predictive models of the OCRA method in the risk assessment of work-related musculoskeletal disorders of the upper limbs. Ergonomics, 50, (11), 1727-1739.

Occhipinti, E., Colombini, D. \& Occhipinti M. (2008). OCRA method : development of a new procedure for analysis of multiple tasks subject to infrequent rotation. Medicina del Lavoro, 99, (3), 234-241. Rebelo, F. (2004). A Ergonomia no Design de Sistemas Físicos e Comunicacionais : Apresentação de Alguns Exemplos. In ERGODESIGN/USIHC - Colectânea de Palestras de Convidados Internacionais e Nacionais. Rio de Janeiro : Edições FAPERJ. Rebelo, F. \& Carvalho, R. (2003). Ergonomics in the Design of a Factory Unit. Comunicação apresentada em International Ergonomics Association and The 7th Joint Conference of Ergonomics Society of Korea / Japan Ergonomics Society "Ergonomics in the Digital Age", Seul, Coreia do Sul, 24 a 29 de Agosto.

Serranheira, F. (2007). Lesões músculo-esqueléticas ligadas ao trabalho : que métodos de avaliação do risco ? Tese de Doutoramento em Saúde Pública na especialidade de Saúde Ocupacional. Lisboa : Escola Nacional de Saúde Pública, Universidade Nova de Lisboa.

Shikdar, A. \& Das, B. (1995). A field study of worker productivity improvements. Applied Ergonomics, 26, 1, 21-27.

Vézina, N. (2001). La pratique de l'ergonomie face aux TMS : ouverture à l'interdisciplinarité. Comptes rendus du Congrès SELF-ACE 2001 - "Les transformations du travail, enjeux pour l'ergonomie", vol. 1, 44-60. 


\section{NOTAS}

1. Algumas das intervenções propostas não foram ainda implementadas, pelo que não é ainda possível avaliar o impacto final desta intervenção. Prevê-se uma fase de introdução das restantes mudanças, novamente em colaboração com os trabalhadores dos postos de trabalho em causa, no sentido de garantir a continuidade da participação efectiva dos operadores no processo de mudança, desde a concepção à implementação.

\section{RESUMOS}

Neste artigo é apresentado um estudo de caso desenvolvido por uma equipa multidisciplinar numa indústria de concepção de transformadores. A intervenção foca-se na interacção dos trabalhadores com os dispositivos envolvidos na realização da actividade, em particular, nas consequências que derivam do facto destes dispositivos não serem desenvolvidos numa perspectiva de design centrado no utilizador. É descrito o contexto particular da intervenção, das tarefas envolvidas na situação de trabalho analisada, bem como os aspectos metodológicos que conduziram a intervenção. São também apresentados os principais resultados da análise, os quais apontam no sentido da necessidade de uma intervenção de reconcepção do posto de trabalho.

Este trabajo presenta un estudio de caso desarrollado por un equipo multidisciplinario en una industria de transformadores. La intervención se centra en la interacción de los trabajadores con los dispositivos involucrados en la realización de la actividad, más específicamente, en las consecuencias que se derivan del hecho de que estos dispositivos no se desarrollasen desde la perspectiva de un diseño centrado en el usuario. El estudio también describe el contexto de la intervención, las tareas involucradas en la situación de trabajo analizada y las cuestiones metodológicas que llevaron a esta intervención. Por último, se exponen los principales resultados del análisis, que sugieren la necesidad de intervenir en un rediseño del puesto de trabajo.

Cet article présente une étude de cas développée par une équipe pluridisciplinaire au sein d'une entreprise de transformateurs. L'intervention a privilégié l'interaction des travailleurs avec les équipements convoqués dans la conduite de l'activité et a analysé en particulier les conséquences du fait que ces équipements n'ont pas été élaborés dans une perspective de conception centrée sur l'utilisateur. Il décrit le contexte particulier de l'intervention, les tâches liées à la situation de travail analysées, ainsi que les questions méthodologiques qui ont soutenu l'intervention. Nous présentons également les principaux résultats de l'analyse, qui suggèrent la nécessité d'une intervention de réaménagement du poste de travail.

This paper presents a case study developed by a multidisciplinary team in a transformer production industry. The intervention focuses on human-machine interaction during the period of activity and particularly on its consequences when the conception of the machine is not usercentered developed. It describes the particular context of the intervention; and the tasks involved in the analysed work situation, as well as the methodological issues that led to the intervention. The main results of the analysis are presented, suggesting the need for intervention by redesigning the job. 
ÍNDICE

Mots-clés: design ergonomique, design participatif, reconception

Palavras-chave: design ergonómico, design participativo, reconcepção

Palabras claves: diseño ergonómico, diseño participativo

Keywords: ergonomic design, participative design, redesign

\section{AUTORES}

\section{SARA RAMOS}

Instituto Superior de Ciências do Trabalho e da Empresa - Instituto Universitário de Lisboa, Av ${ }^{\mathbf{a}}$ das Forças Armadas, 1649-026 Lisboa

sara.ramos@iscte.pt

\section{INÊS GONÇALVES}

Laboratório de Ergonomia - Faculdade de Motricidade Humana, Universidade Técnica de Lisboa, Estrada da Costa - Cruz Quebrada, 1495-688 Cruz Quebrada-Dafundo, Portugal inesgoncalves@gmail.com

\section{HUGO SIMÕES}

Laboratório de Ergonomia - Faculdade de Motricidade Humana, Universidade Técnica de Lisboa, Estrada da Costa - Cruz Quebrada, 1495-688 Cruz Quebrada-Dafundo, Portugal simoeshugo@hotmail.com

\section{FRANCISCO REBELO}

Laboratório de Ergonomia - Faculdade de Motricidade Humana, Universidade Técnica de Lisboa, Estrada da Costa - Cruz Quebrada, 1495-688 Cruz Quebrada-Dafundo, Portugal

frebelo@fmh.utl.pt 